\title{
Fontes e evolução do princípio do equilíbrio contratual
}

\section{Sources and evolution of the principle of contractual balance}

\author{
Carlos Edison do Rêgo Monteiro Filho* \\ Fernanda Paes Leme Peyneau Rito*
}

\section{Resumo}

$\mathrm{Na}$ teoria contratual contemporânea, os princípios clássicos da autonomia privada, da obrigatoriedade dos pactos e da relatividade devem ser relidos à luz dos princípios da boa-fé objetiva, da função social e do equilíbrio contratual. O presente trabalho propõe o estudo do princípio do equilíbrio contratual em perspectiva funcional, devendo o intérprete proceder à análise (não apenas das prestações pactuadas expressamente, mas) da relação jurídica como processo. Empreende a análise crítica das fontes e evolução do princípio do equilíbrio, bem como da jurisprudência do Superior Tribunal de Justiça sobre o tema.

Palavras-chave: Direito contratual. Princípios contratuais. Estrutura e função. Ordem econômica constitucional. Equilíbrio funcional.

\section{Abstract}

In contemporary contract theory, the classic principles of the private autonomy, the obligation of agreements and the relativity must be re-read in the light of the principles of objective good faith, social function and the contractual balance. This paper proposes the study of the principle of contractual balance

Mestre e Doutor em Direito pela UERJ. Professor Adjunto da Faculdade de Direito da UERJ. Foi Coordenador do Programa de Pós-Graduação em Direito da UERJ e Vice-diretor da Faculdade de Direito da UERJ. Procurador do Estado do Rio de Janeiro. Rio de Janeiro - Rio de Janeiro Brasil. Email: carlos_edison@uol.com.br

* Doutora em Direito Civil pela UERJ (2016). Mestra em Direito Civil pela UERJ (2011). Advogada. Professora de Direito Civil do IBMEC e da Cândido Mendes (graduação). Professora de Direito Civil do CEPED/UERJ, da PUC-RJ e da EMERJ. Rio de Janeiro - Rio de Janeiro - Brasil. Email: fer_paesleme@yahoo.com.br 
in functional perspective, in which case the interpreter hereof shall examine (not only the benefits expressly agreed upon, but) the legal relationship as a process. Undertakes a critical analysis of the sources and evolution of the principle of contractual balance, and the precedents of the Superior Court of Justice on the subject.

Keywords: Contract law. Contractual principles. Structure and function. Constitutional economic order. Functional balance.

\section{Introdução}

A dogmática civil tradicional ergueu-se baseada em categorias abstratas: sujeito de direito, direito subjetivo, negócio jurídico, dentre outras que permeiam a disciplina há séculos. A técnica da abstração fezse instrumento que atendia às finalidades principais e convergentes de garantia da igualdade formal e da liberdade jurídica, tendo como ponto de referência o indivíduo e suas manifestações de vontade. Nesse contexto ideológico, desenvolveu-se a teoria contratual clássica.

A idealização do conceito abstrato de sujeito de direito e a tutela de sua vontade livremente declarada revelaram-se importantes formas encontradas pelos códigos oitocentistas para abolir privilégios e tratamentos diferenciados presentes no contexto social e político anterior, de índole absolutista. Sedimentavam-se, assim, os ideais de igualdade e de liberdade, baluartes do Estado Moderno. (RODOTÀ, 2007, p. 13). Ao poder público caberia assegurar as regras do jogo e o controle de validade da atividade econômica privada, de modo a possibilitar o livre trafegar das relações jurídicas. Daí decorria a relevância dos princípios da autonomia privada, da obrigatoriedade dos pactos e da relatividade dos efeitos negociais. Hoje, tais princípios conservam seu vigor, mas, remodelados, atuam em paralelo aos princípios da boa-fé objetiva, da função social e do equilíbrio contratual.

Cumpre destacar que, dos três novos princípios desenvolvidos pela teoria contratual contemporânea, evidencia-se déficit no tratamento 
legislativo, doutrinário e jurisprudencial do equilíbrio das prestações em relação a seus congêneres boa-fé objetiva e função social. $O$ fato de o Código Civil não ter abordado explicitamente o equilíbrio não exclui a importância do princípio na economia dos contratos, de modo que se faz mister analisar seus fundamentos e funções no ordenamento jurídico, a bem de sua aplicação prática pelos operadores do Direito.

A Constituição de 1988, por possuir feição compromissória, a albergar zonas de tensão entre ideias antagônicas, fixou, a um lado, o princípio da livre iniciativa e, a outro, o da solidariedade social, de cuja compatibilidade se extrai a caracterização do equilíbrio econômico das avenças. Sem descuidar da autonomia das partes, a axiologia constitucional sugere a presença do equilíbrio entre as prestações pactuadas, eis que a solidariedade rejeita o desequilíbrio disfuncional. Daí, portanto, desenvolver-se, neste artigo, contribuição no sentido de descortinar limites e possibilidades do princípio, por meio do oferecimento de subsídios teóricos para que o equilíbrio se faça instrumento dos valores constitucionais. Assim, dentre as consequências da releitura do princípio, tem-se que o equilíbrio, em perspectiva dinâmica, não deve ser aferido pontualmente com base em aspectos singulares do contrato, mas sim tomando-se em conta a complexidade da relação em sua inteireza, a caminho do que se pode denominar equilíbrio funcional.

\section{A perspectiva estática do princípio do equilíbrio}

A noção de que os homens eram formalmente iguais em direitos e livres em seu exercício ensejou a formação do Direito caracterizado por alto grau de generalidade e abstração, calcado em ideal cientificista, supostamente apto a solucionar todos os questionamentos a partir de esquemas lógico-dedutivos - a forjar mecanismo assecuratório da previsibilidade. Não obstante a importância de tal construção, considerando-se o contexto de ruptura com o modelo até então vigente, o procedimento da abstração acabou por implementar, por meio da utilização prática de conceitos e categorias jurídicas gerais, uma espécie de neutralização que ocultava a realidade, na medida em que 
a base sob a qual tal construção foi erguida era a igualdade formal e, consequentemente, a liberdade condicionada ao pertencimento de fato, na tal categoria de sujeito de direito.

Explica-se: a igualdade formal, ou igualdade perante a lei, vincula apenas o aplicador do direito, a impor que "toda norma jurídica seja aplicada a todos os casos que sejam abrangidos por seu suporte fático, e a nenhum caso que não o seja, o que nada mais significa do que dizer que as normas jurídicas devem ser cumpridas". (ALEXY, 2008, p. 394). E como era a própria lei que definia o espaço no qual o sujeito de direito iria exercer a sua autonomia, as garantias de isonomia e liberdade restringiam-se quase que integralmente ao âmbito da propriedade e do contrato.

Essa ambiência jurídica determinou o desenvolvimento da teoria contratual clássica, construída, como não surpreende, a partir dos pressupostos da igualdade e da liberdade. Enalteciam-se a vontade livre e a igualdade entre os contratantes - ambos aptos a zelar por seus próprios interesses. Da junção desses pressupostos - igualdade e liberdade - derivava a máxima "se é contrato, é justo", porque "se foi querido pelas partes, resultou da livre apreciação dos respectivos interesses pelos próprios contratantes. Teoricamente, o equilíbrio das prestações é de presumir-se, pois". (BESSONE, 1997, p. 25).

Assim, o direito privado, especificamente o direito contratual, a partir dos séculos XIX e XX, ergue-se sobre a base do princípio da autonomia, resultante da junção da vontade com a liberdade. De maneira que a fonte primordial do direito privado se encontrava no próprio indivíduo e em sua liberdade. Sob tal perspectiva, a autonomia era compreendida como verdadeiro dogma, a expressar o valor da liberdade individual. Essa concepção da autonomia, em via de mão dupla, justificava-se na necessidade de preservação da igualdade meramente formal, visto que "somente com a garantia da auto-regulamentação concedida a cada um, abstratamente considerado, prescindindo das condições ou das circunstâncias individuais seria possível manter a igualdade de tratamento". (PERLINGIERI, 1999, p. 277-278). 
O conteúdo da vontade, manifestado pelo exercício da ampla liberdade de contratar, não sofria, de fato, controle estatal, na medida em que não havia interesse na verificação de o contrato ser justo ou injusto, mas, apenas, no controle de sua licitude. Na perspectiva liberal, o ordenamento jurídico "não se preocupa que o contrato seja objetivamente justo ou equitativo [...], mas preocupa-se, sobretudo, que ele seja cumprido regularmente" (ROPPO, 2009, p. 247-248). Importante era assegurar a vontade livre, invalidando, portanto, pactos resultantes da vontade viciada. A justiça contratual, portanto, resultava do próprio processo de formação do contrato.

Em síntese, o direito moderno e a teoria contratual desenvolvida nesse contexto alocaram a vontade individual no centro do direito privado, consagrando a sua força jurídica. O positivismo legalista que surge a partir de então passa a se ocupar de garantir a validade da vontade livremente declarada e os efeitos obrigatórios dela decorrentes.

A exacerbação da tutela da manifestação da vontade determinava, como consequência, verdadeiro processo de abstração do tratamento jurídico dos elementos essenciais do contrato, especialmente sujeito e objeto. Com efeito, se os sujeitos, abstratamente considerados, eram iguais, tal isonomia (formal), mais do que garantir a todos a capacidade de contrair direitos e obrigações, conferia legalidade e aparente legitimidade a todas as relações estabelecidas, ainda que desiguais.

Do objeto, por seu turno, exigiam-se apenas licitude, possibilidade e determinabilidade. Não havia preocupação efetiva com o conteúdo da relação, com o equilíbrio das prestações assumidas, visto que este era um dado pressuposto, ou consequência lógica dos pactos, uma vez preenchidos seus requisitos formais. Desse modo, "ao direito civil cumpriria garantir à atividade privada e, em particular ao sujeito de direito, a estabilidade proporcionada por regras quase imutáveis nas suas relações econômicas. Os chamados riscos do negócio, advindos do sucesso ou do insucesso das transações, expressariam a maior ou menor inteligência, a maior ou menor capacidade de cada indivíduo". (TEPEDINO, 1999, p. 3). 
O cenário só viria a mudar drasticamente, no Brasil, com a promulgação da Constituição de 1988 que, a um só tempo, representou a fragmentação do modelo contratual clássico, bem como determinou as bases para sua reconstrução em conformidade com a axiologia constitucional, notadamente a partir da incidência dos princípios da dignidade da pessoa humana e da solidariedade social, os quais, em conjunto, promoveram transformação qualitativa no conteúdo da autonomia privada e impuseram a funcionalização do contrato aos valores constitucionais.

Importa destacar que a passagem do qualificativo "da vontade" para "privada", aposto ao substantivo "autonomia" em diferentes contextos histórico-sociais, já indica que a autonomia, não tanto no seu conceito técnico-estrutural, masno seu conteúdovalorativo, devesercompreendida em uma perspectiva relacional e evolutiva. A expressão autonomia da vontade, concebida nas codificações do século XVIII, associada ao voluntarismo jurídico é caracterizada por uma concepção negativa da liberdade individual, já que estabelece verdadeiro impedimento para qualquer interferência externa. Mais contemporaneamente, o emprego da expressão autonomia privada significa uma alteração substancial de conteúdo, na medida em que a valoração e a limitação da liberdade, seu fundamento, foram reformulados em decorrência da nova axiologia constitucional, personalista e solidarista.

$\mathrm{Na}$ esteira de tal evolução, a concepção de autonomia, especificamente por força do princípio da dignidade da pessoa humana, como afirma Gustavo Tepedino (2007, p. 309-320), sofreu tríplice transformação em seus aspectos objetivo, subjetivo e formal, sendo certo que ditas alterações refletem a concepção atual de que a autonomia não é um valor em si, o que implica o juízo de merecimento do ato derivado do exercício da liberdade. (PERLINGIERI, 1997, p. 17-19). Ao mesmo tempo, impõe a funcionalização dos contratos aos valores constitucionais.

Em apertada síntese, o potencial transformador da Constituição de 1988 encontrou no plano do direito das obrigações e dos 
contratos terreno fértil para a promoção dos valores humanistas que protagonizam o ordenamento. Por meio da fixação de seus princípios gerais, orientadores de todo o sistema jurídico, a Constituição, a um só tempo, albergou os alicerces da teoria contratual clássica (igualdade e liberdade), mas impôs sua reconstrução. Assim, inverteu a ordem de prevalência dos interesses em jogo (do sujeito de direito à pessoa, do individual ao social), renovando em definitivo a lógica pretensamente abstrata e imutável das bases da teoria obrigacional clássica.

A igualdade formal e a liberdade revigoram-se por força dos princípios da dignidade da pessoa humana e da solidariedade social. E o reconhecimento da dignidade da pessoa humana como valor máximo do ordenamento priorizou a tutela do ser em relação à do ter; e, ao estabelecer a solidariedade social como objetivo fundamental, impôs a tutela dos interesses coletivos e difusos para além das relações internas de contratantes e proprietários.

\section{Projeções da ordem econômica constitucional na atividade negocial}

Toda atividade econômica desenvolvida em determinado contexto social não pode ser compreendida como mero fato extrajurídico. Certamente, como ramo científico autônomo, a Economia possui racionalidade própria. Contudo, trata-se de uma ciência que se afasta da abstração teórica, porquanto forjada para a aplicação concreta do exercício da atividade econômica, que, por sua vez, se desenvolve em um contexto juridicamente regulamentado (GOMES; VARELA, 1977, p. 74-75).

A ordem jurídica conforma a ordem econômica (REALE, 2011, p. 20). E, mais precisamente, a Constituição assume o papel de determinar qual o modelo econômico compatível com os objetivos do ordenamento vigente. Como sublinhado por Pietro Perlingieri (2003, p. 271-272), entre o mercado e o direito há uma inseparabilidade lógica e histórica, na medida em que o mercado se caracteriza, ao mesmo tempo e por 
definição, como uma instituição econômica e jurídica, pautado por escolhas políticas. E, por essa razão, configura-se como lócus onde a liberdade econômica encontra-se historicamente definida por um contexto cultural e normativo.

O contrato, por ser instrumento a serviço da operacionalização das atividades econômicas, insere-se na ordem econômica, tendo um regime diretamente influenciado pelas opções jurídicas conformadoras de todo o sistema ao qual pertence. Isso porque os contratos são

condutos da ordenação dos mercados, impactados por normas jurídicas que não se contém nos limites do direito civil: preceitos que instrumentam a intervenção do estado sobre o domínio econômico, na busca de soluções de desenvolvimento e justiça social. (GRAU, 2012, p. 92).

Em virtude do paradigma da unidade da Constituição, concluise que inexiste hierarquia normativa entre seus dispositivos, apesar de ser possível identificar-Ihes funções distintas. Com base nessa premissa, Luís Roberto Barroso (2004, p. 155), identifica três categorias de princípios constitucionais: i) princípios fundamentais: "aqueles que contêm as decisões políticas estruturais do Estado”, constituindo o núcleo imutável do sistema; ii) princípios gerais: desdobramentos dos primeiros e que se irradiam por todo o sistema; e, por fim, iii) princípios setoriais ou especiais: "aqueles que presidem um específico conjunto de normas afeto a determinados temas". (BARROSO, 2004, p. 156).

Segundo essa sistematização, a dignidade da pessoa humana, a livre iniciativa, e o valor social do trabalho inserem-se na categoria dos princípios fundamentais, sendo certo que os dois últimos, quando analisados no bojo da ordem econômica, conformam-se como princípios setoriais. Já a solidariedade e a igualdade substancial, extraídas dos objetivos de construção de uma sociedade livre, justa e solidária, e da erradicação das desigualdades, definem-se como princípios gerais. Depreende-se, portanto, que a concretização dos princípios setoriais deve ser feita em harmonia com os princípios fundamentais e os gerais. 
O constituinte definiu, nos artigos iniciais do texto constitucional, sob a forma de fundamentos e objetivos, uma sistemática de vanguarda, condicionante de todo o corpo normativo, tanto constitucional, quanto infraconstitucional. Essa nova ordem pública, como ressaltado por Gustavo Tepedino (2008, p. 80), "eleva ao ápice do ordenamento a tutela da pessoa humana, funcionalizando a atividade econômica privada aos valores existenciais e sociais ali definidos". E, para não restar qualquer dúvida, o constituinte expressamente condiciona a livre iniciativa a esses valores, quando disciplina a ordem econômica.

A transposição do princípio da livre iniciativa para a ordem econômica é expressa no caput do artigo 170, que traz a valorização do trabalho humano como fundamento da ordem econômica, tal como a livre iniciativa, tendo por fim assegurar a todos existência digna, conforme os ditames da justiça social. Assim, nos termos do dispositivo em comento, o exercício de toda atividade econômica resta comprometido "com o programa de promoção da existência digna” (GRAU, 2012, p. 194), de sorte que qualquer desvio desse fim expressa violação à própria Constituição.

Desse modo, a atividade econômica desenvolvida no âmbito da iniciativa privada, expressão do princípio da livre iniciativa, só será digna de tutela se o seu escopo convergir com os ditames dos princípios de funcionamento. Não se pode, por óbvio, impor ao particular o objetivo de concretizar os princípios-fins, de maneira a desvirtuar o cerne lucrativo de sua atividade para subjugá-la ao assistencialismo, que deve ser cumprido, a priori, pelo Estado. Contudo, deve o particular atender, na persecução da sua finalidade própria, a função social da empresa, o respeito ao valor social do trabalho, aos direitos do consumidor, a preservação do meio ambiente e, também, a manutenção e o respeito à livre concorrência, abstendo-se do exercício disfuncional da liberdade de iniciativa.

Isso porque a livre iniciativa, como princípio da ordem econômica constitucional, não representa a opção pelo regime de economia de mercado na acepção da ortodoxia liberal, mas sim, no sentido da livre 
concorrência e da não necessidade, via de regra, de autorização estatal para o desempenho de atividades econômicas lícitas. Nesse sentido, o Supremo Tribunal Federal já afirmou que "o princípio da livre iniciativa não pode ser invocado para afastar regras de regulamentação do mercado e de defesa do consumidor". (BRASIL. STF. 2a T. RE 349.686. Rel. Min. Ellen Gracie, julg.: 14/06/2005, DJ: 05/08/2005). Já o seu conteúdo abrange a propriedade privada, como "apropriação particular dos meios de produção (art. 5, XXI e 170, II) (BARROSO, 2008, p. 4); a liberdade de exercício de qualquer atividade econômica, salvo os casos previstos em lei (art. 170, parágrafo único), a qual manifesta-se principalmente na atividade empresarial (AMARAL, 1986, p. 229); a livre concorrência, que permite a livre fixação, como regra, dos preços em um ambiente de mercado competitivo (art. 170, IV); e, por fim, manifesta-se na liberdade de contratar.

A livre concorrência, nessa perspectiva, apresenta-se como desdobramento da livre iniciativa, abrangendo aspectos de liberdade pública e de liberdade privada. No prisma da liberdade pública, a livre concorrência impõe a neutralidade do Estado diante da concorrência leal e a criação de condições equitativas entre partes naturalmente desiguais. (BARROSO, 2008, p. 10). Já sob a forma de liberdade privada, encerra tanto o direito dos agentes privados à livre concorrência, quanto o dever de abstenção de adotarem comportamentos anticoncorrenciais.

Uma vez que o constituinte condicionou o sistema capitalista de mercado à promoção da pessoa e dos valores sociais, a livre concorrência se apresenta como o princípio constitucional impositivo. (GRAU, 2012, p. 197). A delimitação do seu conteúdo é informada, dentre outras, pela decisão política de repressão ao abuso do poder econômico (art. 173, $\$ 4^{\circ}, \mathrm{CF}$ ). Isso porque a Constituição, ao estabelecer a livre concorrência como princípio da ordem econômica, parte da igualdade jurídico-formal dos agentes econômicos. E, dessa forma, consegue-se garantir-lhes a liberdade privada sem, no entanto, ignorar a inexorável desigualdade fática entre eles (PRADO, 2014, p. 42-43), considerada como tolerável desde que não seja impeditiva para o exercício da liberdade dos demais e não contrarie os valores informadores do sistema (o que justifica, 
por exemplo, o tratamento diferenciado à microempresa e a proteção especial ao consumidor).

Em suma, os princípios (art. $1^{\circ}, \mathrm{CF}$ ) e os objetivos fundamentais (art. $3^{\circ}, \mathrm{CF}$ ) do Estado brasileiro e os princípios setoriais da ordem econômica (art. 170, CF) impuseram profunda transformação às relações jurídicas privadas patrimoniais. (TEPEDINO, 2007, p. 309). Especificamente, da junção das previsões constitucionais citadas, emerge a concepção social do contrato, na qual as características das partes contratantes, assim como o objeto do contrato, antes desconsiderados ganham relevância jurídica, de forma a atrair dogmática própria.

A liberdade patrimonial, consubstanciada na livre iniciativa, continua a ser tutelada, por certo, mas é funcionalizada, por opção do constituinte democrático, aos valores da pessoa humana e da solidariedade social (KONDER, 2006, p. 26). Como destacado por Luiz Edson Fachin e Gabriel Schulman (2008, p. 362), a axiologia constitucional e, em especial, a ordem econômica constitucional incidem no âmbito contratual, não para eliminar a autonomia privada, mas para determinar parâmetros para o seu exercício, concluindo que a ordem econômica constitucional não pode ser associada nem à "economia do mercado", nem à "economia sem mercado", mas a um determinado arranjo dinâmico, cuja nova feição está, reitera-se, na dialética dos interesses particulares e sociais".

\section{A perspectiva dinâmica do princípio do equilíbrio: a caminho do equilíbrio funcional dos contratos}

O princípio da obrigatoriedade, representado pelo brocardo latino pacta sunt servanda, foi idealizado como corolário da autonomia da vontade tal como concebida nos diplomas oitocentistas. À época, os códigos se associavam ao voluntarismo jurídico, cujos traços notadamente subjetivos, psicológicos, elevavam a vontade do sujeito de direito a fonte quase que exclusiva dos efeitos obrigacionais. 
Essa concepção da autonomia, como já destacado no ponto 2, supra, sofreu transformação qualitativa em decorrência da incidência do princípio da dignidade da pessoa humana. E, como consequência direta da redefinição dos contornos valorativos da liberdade individual, os atos de autonomia são submetidos ao controle de merecimento de tutela. Assim, além de atender ao critério da licitude/ilicitude, o ato de autonomia tem que atender também ao critério da legitimidade. Dito diversamente, o primeiro limite imposto à autonomia privada afigura-se negativo, consubstanciado no critério da licitude/ilicitude. Este sempre existiu e corresponde ao princípio da legalidade, que determina não ser possível fazer aquilo que a lei proíbe. Contudo, em um ordenamento promocional, a licitude não é critério bastante para a valoração em termos positivos do ato de autonomia.

Significa dizer que todo e qualquer ato de autonomia será analisado como instrumento jurídico dinâmico. Somado ao juízo de licitude/ ilicitude, o intérprete também deverá se valer de critérios qualitativos, por meio dos quais se consiga avaliar a legitimidade do ato à luz dos contornos constitucionais que lhe dão fundamento e da função que deva desempenhar no caso prático. A título de exemplo, alguns parâmetros para o controle de legitimidade encontram-se disciplinados no artigo 187 do Código Civil de 2002, a saber: fim econômico ou social, boa-fé e bons costumes. "Nos contratos, a abusividade será sempre identificada diante da contrariedade do exercício da posição contratual por uma das partes à causa ou função negocial”. (SOUZA, 2013, p. 65-98).

À luz dessa nova conformação, o princípio da obrigatoriedade, que pode ser destrinchado em dois substratos que se complementam e retroalimentam: a obrigatoriedade stricto sensu, a significar que as cláusulas convencionadas têm força de lei entre as partes (lex inter pars) e a intangibilidade, segundo a qual ao juiz não seria consentido intervir no objeto pactuado, que apenas poderia ser desfeito ou modificado por nova manifestação de vontade daquelas mesmas partes contratantes, deve ser revisitado e adequado, especialmente no substrato da intangibilidade. (PERLINGIERI, 1999, p. 278). Ocorre que, se o contrato revela manifestação clara de autonomia das partes, necessariamente 
tem que existir espaço para avaliação de conformidade do seu conteúdo, não apenas em relação à vontade das partes, mas com respeito ao ordenamento, os seus valores e princípios informadores. Nesse sentido, Karl Larenz (2001, p.79-80) pondera que, se a validade de um contrato depende do seu reconhecimento pelo ordenamento jurídico positivo no qual se manifesta, o seu conteúdo não pode ser indiferente a esse mesmo ordenamento.

O conteúdo da justiça contratual deve ser buscado, assim, dentro do exato contexto histórico-social no qual o negócio, que se pretende justo, se manifesta. Em uma sociedade democrática, tal qual a brasileira, inspirada por valores personalistas e solidaristas, liberdade e igualdade jurídicas revelam-se pilares fundamentais, não cabendo ao Estado intervir, a priori, diretamente nas relações privadas, salvo para assegurar a efetividade de direitos fundamentais.

Exatamente por isso a noção de justiça contratual não pode mais ser compreendida como o resultado do somatório da liberdade e da igualdade formais. Se o Direito Civil busca atender "a liberdade da pessoa concreta em suas relações intersubjetivas e no livre desenvolvimento de sua personalidade" (RUZYK, 2011, p. 4), deve-se privilegiar a concretização da liberdade efetiva e da igualdade material. Com efeito, essa meta legitima a atuação preventiva do legislador, ao restringir a liberdade formal de uma parte a fim de promover os interesses do contratante mais vulnerável, ditando normas protetivas para certos grupos, como os consumidores, por exemplo.

Consequentemente, a noção de justiça contratual é reformulada por força do solidarismo constitucional, de sorte que já não satisfaz a ideia de justiça contratual formal, baseada na noção de que o contrato pressuporia equivalência entre as prestações, visto ter sido celebrado por pessoas livres e iguais.

O controle do conteúdo dos contratos não é estranho ao ordenamento jurídico brasileiro. A rigor, verificam-se diversos dispositivos legais direcionados à coibição da desproporção (parâmetro comparativo), por meio dos quais o legislador não só limita, ou melhor, condiciona a 
liberdade das partes aos valores do ordenamento, como indica que no exercício da sua função interpretativa, o juiz pode integrar e/ou intervir nos pactos, a fim de reequilibrá-los e conservá-los, observando para tanto a equidade, especialmente em suas funções interpretativa e corretiva (AMARAL, 2004, p. 17).

Por esse motivo, a proporcionalidade é eleita como parâmetro comparativo entre as obrigações contrapostas em um contrato. Além disso, como destacado por Pietro Perlingieri (2008, p. 404-405), a proporcionalidade favorece e concretiza outros princípios e valores normativos de relevância constitucional e incide "profundamente sobre a moderna concepção de contrato que, desse modo, distancia-se definitivamente da tradicional interpretação voluntarista do princípio do pacta sunt servanda".

Nessa perspectiva, no âmbito das relações contratuais, a proporcionalidade dá a medida da igualdade, informando a legitimidade e adequação do tratamento desigual entre os sujeitos. De outro turno, fornece subsídios para eventuais limitações da liberdade, seja por meio da atuação preventiva do legislador, seja pela atuação interpretativa e corretiva do julgador.

O desempenho da função corretiva se dá especialmente na seara dos contratos, a exemplo da redução da cláusula penal, prevista no artigo 413 do Código Civil, bem como da possibilidade de o juiz revisar o valor da prestação devida que, por fatores supervenientes e imprevisíveis, tenha se tornado manifestamente desproporcional quando comparado ao momento da constituição do vínculo obrigacional (art. 317, Código Civil).

Em síntese, a escolha do legislador de 2002, em relação ao dever do juiz em reduzir equitativamente a cláusula penal nas hipóteses de cumprimento parcial ou de excessiva onerosidade, evidencia que o ordenamento jurídico brasileiro admite o controle judicial do conteúdo dos pactos, a fim de estabelecer o equilíbrio objetivo das relações contratuais, em hipóteses outras que não as expressamente previstas 
na disciplina dos vícios do consentimento e da onerosidade excessiva por fatos supervenientes.

Ainda que não exclusivamente, apresenta-se não só viável, mas de todo conveniente estender a atuação corretiva do magistrado a todas as situações de desequilíbrio ou desproporção manifestas. Em síntese, o recurso à equidade e os parâmetros introduzidos pelo legislador no artigo 413 devem ser utilizados para a operacionalização do princípio do equilíbrio funcional dos contratos. Deve-se, portanto, reconhecer na regra estatuída no artigo 413 potencial expansivo capaz de permitir o controle objetivo da autonomia privada, aplicável, por analogia, a outras situações de desequilíbrio objetivo.

Esse controle do conteúdo, no entanto, não pode significar anulação da autonomia das partes. O contrato é instrumento para autorregulação dos interesses das partes contratantes. Trata-se de um controle de abusividade a ser exercido pelo magistrado, em atenção a todo o programa contratual estabelecido pelas partes (prestações principais, secundárias, acessórias, ônus, prerrogativas, etc.) e durante toda a sua existência.

Não se resume, pois, ao equilíbrio das prestações principais apenas, na medida em que a proporcionalidade não é meramente quantitativa, mas, sobretudo, qualitativa. Assim, deve ser invocada, por exemplo, sempre que a uma das partes se reserva faculdades que são injustificadamente recusadas à outra, bem como quando uma das partes impõe a outra parte ônus, dos quais injustificadamente se exonera. Ademais, leva em consideração não só o momento formativo do consentimento e/ou a superveniência de fatores externos, mas todo o conjunto contratual, apreciado de forma integral, unitária e dinâmica, e guiado pela noção de proporcionalidade.

Nesse sentido, observa-se que o estudo do equilíbrio contratual não deve ser realizado pontualmente apenas no tocante à determinada obrigação estaticamente considerada, mas de forma global, levando em conta a relação jurídica como um todo, a abranger as especificidades de cada situação jurídica em concreto, em perspectiva dinâmica. 
$\mathrm{Na}$ busca do equilíbrio funcional, devem ser avaliadas, por exemplo, circunstâncias contratuais além daquelas traduzidas nos clássicos binômios preço-serviço ou preço-coisa. Em uma sociedade fluida e de massificação do consumo, impõe-se observar fatores como o risco assumido por cada contratante, além de juros, cláusulas penais, cláusula resolutiva expressa, dentre outros. A busca do equilíbrio requer a investigação ampla da relação, o que impõe ao intérprete o dever de mirar também aspectos negociais não clausulados e até mesmo eventuais coligações contratuais.

\section{Análises de casos}

Fixadas as premissas teóricas, passa-se à análise da aplicação do princípio do equilíbrio funcional na jurisprudência, mais especificamente no que se refere ao artigo 413 do Código Civil. Conforme mencionado alhures, o dispositivo contempla o dever de redução da cláusula penal pelo magistrado nas hipóteses de cumprimento parcial e/ou excessividade manifesta do seu montante, conforme a natureza e a finalidade do negócio.

A rigor, a partir da aplicação do artigo 413, principalmente, o Superior Tribunal de Justiça vem procedendo claramente à necessária releitura do direito contratual, a partir de uma ponderação entre autonomia, igualdade e justiça material. Dois julgados em especial evidenciam a preocupação com o equilíbrio das relações contratuais, bem como a possibilidade de alargamento ou redução do conteúdo contratual em prestígio ao equilíbrio.

No julgamento do Recurso Especial $n^{\circ} 1.119 .740$, de relatoria do Ministro Massami Uyeda, a questão central cingia-se em definir se a cláusula penal inserida em um contrato e dirigida a um dos contratantes apenas poderia ser imposta ao outro. Tratava-se de uma promessa de compra e venda realizada entre uma incorporadora imobiliária (promitente-vendedora) e uma pessoa natural (promitente-compradora), 
antes da vigência do Código de Defesa do Consumidor, razão pela qual tal diploma não foi aplicado para o deslinde.

A incorporadora inadimpliu a sua obrigação, retardando a entrega do imóvel em 14 anos e, em virtude da mora, a promitente-compradora exigiu judicialmente a aplicação da cláusula penal que, nos termos do contrato, incidiria exclusivamente em desfavor da adquirente, na eventualidade do seu inadimplemento. Em primeiro e segundo graus, o pedido foi julgado improcedente, aos fundamentos principais da preservação da autonomia da vontade das partes e do respeito ao princípio do pacta sunt servanda (sentença), bem como da vedação do enriquecimento sem causa, argumento deduzido na decisão em sede de apelação. Os ministros da Terceira Turma do Superior Tribunal de Justiça, por unanimidade, entenderam diversamente. Em cuidadoso voto, o Ministro Relator, apesar de reconhecer o princípio da força obrigatória dos contratos, advertiu para sua relativização à luz dos princípios da boa-fé, da função social e da equivalência. Ressaltou, ainda, que, para se extrair a real declaração volitiva dos contratantes, o intérprete deveria considerar não apenas a literalidade das cláusulas contratuais, mas também o tipo de contrato celebrado e seus efeitos e, a partir dessas considerações, reinterpretar todo o programa contratual à luz dos referidos princípios.

Com base nessa construção e aplicando a proporcionalidade, enquanto parâmetro comparativo, concluiu que, uma vez caracterizado um contrato bilateral, com obrigações recíprocas entre as partes, oneroso e comutativo, não seria proporcional nem razoável que, tendo sido prefixado os danos em uma cláusula penal, apenas uma das partes pudesse de tal cláusula se valer, impondo à outra parte, efetivamente lesada pelo inadimplemento, o ônus de comprovar o efetivo prejuízo suportado por meio de ação própria.

Em seguida, tratou de adequar a cláusula penal aos limites objetivos impostos pelo legislador nos artigos 412 e 413, ambos do Código Civil. A aplicação da fórmula prevista pelas partes para a prefixação das perdas e danos resultava em valor duas vezes e meia superior ao 
valor da promessa de compra e venda. Assim, uma vez reconhecida a incidência da cláusula penal, aplicou-se o limite previsto no artigo 412, que determina que o valor da cominação imposta não pode exceder o da obrigação principal, reduzindo o montante da penalidade até o valor estabelecido no contrato. Em seguida, em observância ao princípio da proporcionalidade e tendo em vista que, não obstante o longo atraso de 14 anos, o imóvel foi entregue, foi aplicada a redução equitativa do artigo 413.

Em outra decisão, o Superior Tribunal de Justiça estabeleceu a correlação entre os aspectos principiológico e parâmetro quantitativo e comparativo da proporcionalidade. Tratava-se do julgamento do Recurso Especial $n^{\circ} 1.186 .789$, de relatoria do Ministro Luis Felipe Salomão.

A controvérsia principal centrava-se na aplicação da cláusula penal em sua integridade ou equitativamente reduzida, em virtude de descumprimento parcial de contrato de prestação de serviços em caráter de exclusividade, celebrado entre a TV Globo Ltda. e o jornalista e apresentador Celso de Freitas. O contrato havia sido celebrado pelo prazo determinado de 51 meses, dos quais os 49 primeiros meses foram cumpridos, perfazendo um adimplemento de aproximadamente 95\% das obrigações pactuadas. Em razão do inadimplemento, a TV Globo Ltda. pretendeu a execução integral da cláusula penal. O juízo de primeiro grau, aplicando o artigo 413 do Código Civil, reduziu o montante em $50 \%$, decisão, nesse aspecto, mantida pelo Tribunal de Justiça do Rio de Janeiro. Ambas as partes interpuseram recurso especial. A parte autora pleiteou a condenação integral, ao argumento principal de que o contrato havia sido firmado de forma irretratável e irrevogável, tendo sido ainda prevista a irredutibilidade da cláusula penal, independentemente do tempo de cumprimento do contrato. Já a parte ré pretendia a redução proporcional da cláusula penal ao efetivo cumprimento, ou seja, pretendia uma redução de $95 \%$ da penalidade.

A sentença destacou que a redução da multa não poderia obedecer à lógica puramente matemática, mas deveria observar os prejuízos efetivos suportados em virtude do inadimplemento. No 
mesmo sentido, e destacando as peculiaridades da relação contratual mantida pelas partes por mais de três décadas, bem como o fato de o inadimplemento ter sido motivado pela migração do profissional para a empresa concorrente, o Tribunal de Justiça do Rio de Janeiro enfatizou que a ruptura no equilíbrio da relação deveria refletir na indenização devida.

Instada a decidir a controvérsia, a Quarta Turma do Superior Tribunal de Justiça, por unanimidade, acolhendo os argumentos deduzidos no acórdão do Relator, manteve a redução da cláusula penal em $50 \%$, confirmando mais uma vez o entendimento de que o Judiciário pode reduzir multa estabelecida em contrato, com a ressalva de que tal redução não pode retirar a função coercitiva ínsita à cláusula penal em caso de ruptura.

A fundamentação da decisão sublinhou dois pontos centrais. Inicialmente, foi ressaltado que, desde a vigência do Código Civil de 1916, prevalece o entendimento pela invalidade do acordo sobre a irredutibilidade da cláusula penal, por se tratar de questão de ordem pública. Em seguida, destacou que a proporcionalidade se insere no juízo de equidade, tendo, portanto, conteúdo normativo e não meramente matemático, concluindo que "a redução equitativa a ser feita pelo juiz quando a obrigação principal tiver sido cumprida em parte não é sinônimo de redução proporcional".

Desse modo, o exame dos julgados evidencia que, para que se analise o equilíbrio de determinada relação jurídica, deve-se empreender detida investigação não somente das prestações expressamente pactuadas num dado instrumento, mas da relação jurídica como processo, contemplando todas as suas circunstâncias. A reformulação não é, em si, inovadora, ao contrário, representa um retorno ao ideal de justiça comutativa. Impende, assim, a apreciação funcional do equilíbrio da relação jurídica em concreto, seguindo o parâmetro da proporcionalidade e com o objetivo de que as relações contratuais sejam efetivamente justas. 


\section{Referências}

ALEXY, Robert. Teoria dos direitos fundamentais. São Paulo: Malheiros, 2008.

AMARAL, Francisco. Direito civil - Introdução. 7. ed. Rio de Janeiro: Renovar, 2008.

A equidade no Código civil brasileiro. Revista CEJ, Brasília, n. 25, p. 16-23, abr./jun. 2004.

. A liberdade de iniciativa econômica. Fundamento, natureza e garantia constitucional. Revista de Informação Legislativa, local, v. 92, p.?-?, 1986.

BARROSO, Luís Roberto. Interpretação e aplicação da constituição. 6. ed. São Paulo: Saraiva, 2004.

. A ordem econômica constitucional e os limites à atuação estatal no controle de preços. Revista Eletrônica de Direito Administrativo Econômico (REDAE). Salvador, Instituto Brasileiro de Direito Público, n.14, p.4, maio/jun./jul. 2008. Disponível em: <http:// www.direitodoestado.com.br/redae.asp> Acesso em: 15 jul. 2015.

BESSONE, Darcy. Do contrato: teoria geral. 4. ed. São Paulo: Saraiva, 1997.

BRASIL. STF. $2^{\mathrm{a}}$ T. RE 349.686. Rel. Min. Ellen Gracie, julg.: 14/06/2005. Diário de Justiça, Brasília, DF, 5 ago. 2005.

FACHIN, Luiz Edson; SCHULMAN, Gabriel. Contratos, ordem econômica e princípios: um diálogo entre o direito civil e a constituição 20 anos depois. In: DANTAS, Bruno et al. (Org.). Constituição de 1988, o Brasil 20 anos depois. Brasília: Senado Federal, 2008. p.?-?. v. IV.

GOMES, Orlando. Contratos. 19. ed. Rio de Janeiro: Forense, 1999. ; VARELA, Antunes. Direito econômico. São Paulo:

Saraiva, 1977. 
GRAU, Eros Roberto. "Um novo paradigma dos contratos?" Revista Crítica Jurídica, local, n. 18, p.?-?, jun. 2001.

A ordem econômica na constituição de 1988. 15. ed.

São Paulo: Malheiros, 2012.

KONDER, Carlos Nelson. Contratos conexos - Grupos de contratos, redes contratuais e contratos coligados. Rio de Janeiro: Renovar, 2006.

LARENZ, Karl. Derecho justo: fundamentos de ética jurídica. Madri: Civitas, 2001.

MEIRELES, Rose Melo Vencelau. Autonomia privada e dignidade humana. Rio de Janeiro: Renovar, 2009.

MONTEIRO FILHO, Carlos Edison do Rêgo. Usucapião imobiliária urbana independente de metragem mínima: uma concretização da função social da propriedade. In: (Coord.). Direito das relações patrimoniais: estrutura e função na contemporaneidade. Curitiba: Juruá, 2014. p.?-?.

PERLINGIERI, Pietro. $O$ direito civil na legalidade constitucional. Rio de Janeiro: Renovar, 2008.

. Perfis do direito civil. Rio de Janeiro: Renovar, 1999.

. Il diritto dei contratti fra persona e mercato: problemi del diritto civile. Napoli: Scientifiche Italiane, 2003.

PRADO, Luiz Regis. Direito penal econômico. 6. ed. São Paulo: RT, 2014.

REALE, Miguel. Lições preliminares de direito. 27. ed. São Paulo: Saraiva, 2011.

RODOTÀ, Stefano. Dal soggetto alla persona. Local: Editoriale Scientifica, 2007.

ROPPO, Enzo. O contrato. Coimbra: Almedina, 2009. 
RUZYK, Carlos Eduardo Pianovski. Institutos fundamentais do direito civil e liberdade(s): repensando a dimensão funcional do contrato, da propriedade e da família. Rio de Janeiro: GZ, 2011.

SCHREIBER, Anderson. O princípio do equilíbrio das prestações e o Instituto da Lesão. In: VENOSA, Sílvio de Salvo; GAGLIARDI, Rafael Villar; NASSER, Paulo Magalhães (Org.). 10 anos do Código civil desafios e perspectivas. São Paulo: Atlas, 2012. p.?-?.

SOUZA, Eduardo Nunes de. Função negocial e função social do contrato: subsídios para um estudo comparativo. Revista de Direito Privado, local, v. 54, p.?-?, 2013.

TEPEDINO, Gustavo. Premissas metodológicas para a constitucionalização do Direito Civil. In: civil. Rio de Janeiro: Renovar, 1999. p.?-?. t. I. . Temas de direito . Normas constitucionais e direito civil na construção unitária do ordenamento. In: SOUZA NETO, Cláudio Pereira, SARMENTO, Daniel (Coord.). A constitucionalização do direito: fundamentos teóricos e aplicações específicas. Rio de Janeiro: Lúmen Júris, 2007. p.?-?.

. Direitos humanos e relações jurídicas privadas. In: Temas de direito civil. 4. ed. Rio de Janeiro: Renovar, 2008. p.?-?.

Recebido em: 03/08/2016

Aprovado em: 24/08/2016 